\title{
ACOUSTIC EMISSION OF CORRODED WELDMENTS DURING TENSILE TEST
}

\author{
Michal SUSTR, Jaroslav ZACAL, Peter DOSTAL, Oldrich CERNY \\ Mendel University in Brno \\ Miroslav PRISTAVKA \\ Slovak University of Agriculture in Nitra \\ David DOBROCKY \\ University of Defence
}

Stefan GASPAR, Jan PASKO

Technical University of Kosice

\begin{abstract}
:
The article deals with the use of acoustic emission to identify the formation of cracks during the mechanical loading in the corrosive attacked weldment S235JR+N. The experiment includes the methodology for continual record of emissive signals, data analysis and monitoring of material response to monitor mechanical stress effect in real time. There is possibility to observe response of corrosive degraded samples in real time during mechanical stress through the suitably designed methodology of detection, process and analysing of acoustic emission signals. It is possible to gain new information about processes rising inside the material by this way of data measurement. The signals of acoustic emission can be used as the way of identification for the micro cracks rising in the inner and also external structure of effortful materials.
\end{abstract}

Key words: weld joint, hot-dip galvanising, corrosion, acoustic emission, protection

\section{INTRODUCTION}

The method utilised in fusion welding is mixing the base and the added metal so that by the subsequent recrystallisation of the weld metal they form a weld. Local fusion is achieved, for example, by means of a flame or by electric resistance $[1,2,3]$. The weldability of the material plays a very important role. Weldability represents the capability of the material to create a weld, by means of which materials are joined together. This weld should have the same properties as the base material $[4,5]$.

Thanks to structural changes of basic material, the join welds are more susceptible to different types of corrosion attacks and that is the reason why they belong to problematic components. These changes rise up during the process of welding and it is impossible to avoid them totally. We use the additional material that is mostly similar to the basic material so that we postponed the creation of the corrosion in the welding joint utmost $[6,12]$.

The alternative possibility leads to the solving of construction modifications to reach the condition of non-excluding supportive substances as that of the leak lapped welding joints.
However, another commonly used method is the use of surface protective modifications. These modifications protect welding joint at longest from the activity of external influences that cause the creation and progress of corrosion and they also significantly affect the life time of welding joint $[8,13,21]$.

Wanting surface modification can leads to degradation of welding joint and this situation can cause the destruction of whole apparatus and construction. Therefore, it is necessary to know the environment character where the welding joint will occur together with planned life time before we start designing the welding joint $[19,22]$.

Non-destructive testing (NDT) is defined as the technical method to examine materials or components in ways that do not impair future usefulness and serviceability. NDT can be used to detect, locate, measure, and evaluate flaws; to assess integrity, properties, and composition; and to measure geo-metric characteristics. Various NDT technologies, such as ultrasonic-based methods, radiographic methods, dynamic methods, acoustic emission $(A E)$ techniques, and acoustoultrasonic (AU) techniques have been studied. Each NDT technique has both advantages and dis-advantages with regard to cost, speed, 
accuracy, and safety A stress source, when it is being released by either external or internal forces, causes expansion $[10,11,12]$. The resultant wavelength incident produces irreversible processes in the material. These processes may be activated, not only during structural and phase changes, for example, but also during the escape of material or during cavitation, and also in regard to biological processes. The energy released during these processes becomes a mechanical stress pulse. This pulse propagates in a waveform in material. It may be a longitudinal or a transverse elastic stress wave. The stress wave propagates from its initiation point towards the AE sensor placed on the surface of the body. Most commonly manifested is the wave character of the development of dynamic elastic stress. The sensor detects both the size and the frequency of the waves and transforms them into an electric signal. This signal is processed in an analogue manner and then evaluated by the AE measurement system. Only in a few special cases a pulse beam is found, ideally propagating at the same speed at the shock edge of the wave front. These include, for example, surface Rayleigh waves, longitudinal wave pulse propagation in a thin rod or the propagation of a symmetrical dilatation wave in a thin plate $[6,17]$.

Acoustic emission is a phenomenon frequently encountered in everyday life. An example of acoustic emission is the sound of a pencil being broken or wood being split. Technically, acoustic emission (AE) is defined as the class of phenomena in which transient elastic waves are generated by the rapid release of energy from a localized source or sources within a material. The term also applies to the transient elastic waves so generated $[15,19]$.

\section{MATERIAL AND METHODS}

\section{Experimental material}

The basic material for production of all samples was chosen preheated rolled unalloyed structural steel S235JR+N which was made to norm EN 10025-2:2004. The suitability for robotic welding of this material was the reason of material option. The basic material took the proportion $2000 \times 1000 \times 2 \mathrm{~mm}$, subsequently was cut into strips in proportions $20 \times 90 \times 2 \mathrm{~mm}$ by the hydraulic scissors ERMAK CNC HGS 2606. The surface modification was created by the hot-dipping plating in the weld pool of the molten zinc. These strips were subsequently welded by the CMT method. For this, the WF 60i ROBACTA DRIVE CMT automated welding center was used. A total of 30 samples were tested. Sample dimensions are shown in Figure 1.
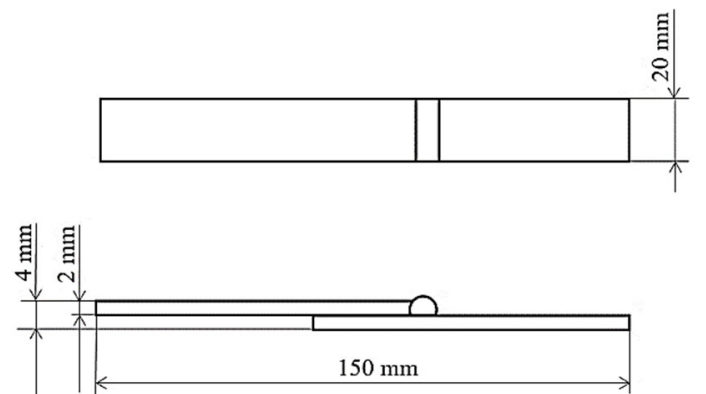

Fig. 1 Scheme of sample
Zinc dipping was applied by the use of the norm ČSN EN ISO 1461. The minimal thickness of slip-cover of experimental samples corresponds to norms. The measuring was realized in two random parts out of the joints. Gained values obtain the range from $58 \mu \mathrm{m}$ to $82 \mu \mathrm{m}$. The chemical structure protective atmosphere for welding process is shown in Table 1.

Table 1

Parameters of welding

\begin{tabular}{cccc}
\hline \multicolumn{2}{c}{ Parameters of welding } & \multicolumn{2}{c}{ Parameters of activ gass } \\
\hline Welding current & 170 & $\mathrm{CO}_{2}[\%]$ & 8 \\
Welding tension & 20 & $\mathrm{Ar}[\%]$ & 91.97 \\
Wire shift & 7.2 & $\mathrm{NO}[\%]$ & 0.03 \\
\hline
\end{tabular}

\section{Measurement system of acoustic emission}

Acoustic emissions ( $A E$ ) are the stress waves generated by the sudden internal stress redistribution in materials or structures when changes in their internal structure are produced (crack initiation and growth, crack opening and closure, deformation, dislocation movement, void formation, interfacial failure, corrosion, fibre-matrix debonding in composites, etc). These waves propagate through the material and eventually reach the surface, producing small temporary surface displacements. Usually the stress waves are of low amplitude and of high frequency (normally, ultrasonic). This is the reason why very sensitive piezoelectric transducers (sensors) are required to capture them. Due to the low amplitude of AE waves, several steps must be sequentially incorporated after their capture and before the subsequent recording and analysis. A preamplifier is necessary to minimise the interference and prevent the signal loss, a filter to remove the noise and an finally an amplifier. Figure 2 shows a block diagram of this procedure.

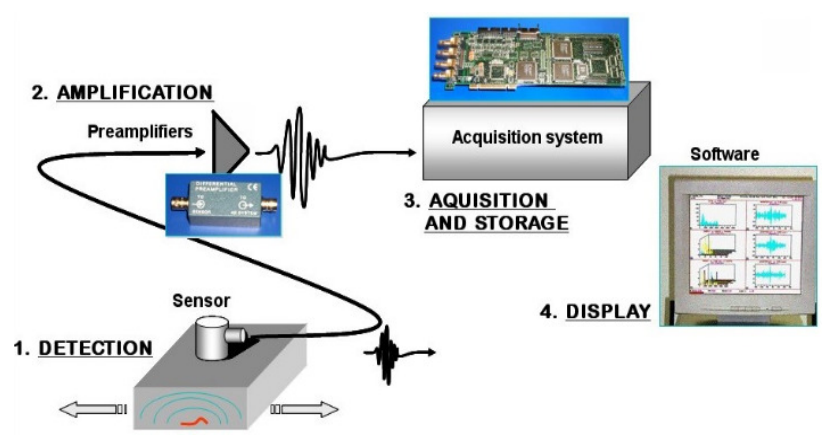

Fig. 2 Block diagram of acoustic emission system

\section{System of corrosion degradation}

The accelerated corrosion tests were performed according ČSN ISO 9227. It was used the corrosion environment - the salt fog (atmosphere of chloride $\mathrm{NaCl}$ ) in concentration $50 \pm 5 \mathrm{~g} \cdot \mathrm{l}^{-1}$ of distilled water. The density of solution with the defined concentration and the $25^{\circ} \mathrm{C}$ temperature is $1.0225-1.0400 \mathrm{~g} \cdot \mathrm{cm}^{-3}$. This test is suitable for metals and their alloys, metal plating or organic plating on metal bases. ISO 9227 is particularly useful for detecting discontinuities, pores and damages in organic and inorganic coatings as well as for assessing the corrosion resistance of metallic materials. It is also a mean to determine if the comparative quality of a metallic material, either with or 
without corrosion protection, is preserved. However, it is important to be aware of the fact that there is no direct correlation between resistance to the action of salt spray and resistance to corrosion as the corrosion stress in enduse conditions are significantly different than the ones during testing. In this way, results should not be used as a comparative guide to the long-term behavior of different coating systems or to rank different materials relative to each other. Figure 3 shows the principle of corrosion chamber.

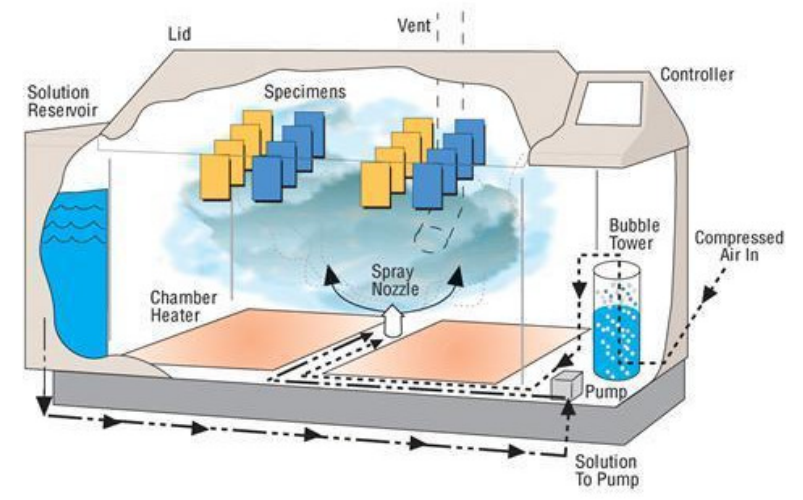

Fig. 3 Corrosion chamber

\section{Experimental methodology}

The welded samples with surface protection of zinc dipping were degraded by corrosive effects in salt chamber. There were 30 samples divided into three groups based on time of corrosion degradation. Samples 1-10 were not corrosive degraded. Samples 11-20 were corroded in corrosion chamber for the time of 100 hours. Samples $21-30$ were corroded for 200 hours.

The universal testing machine ZDM 5/51 was used for tensile test. Figure 4 shows the scheme of this equipment.

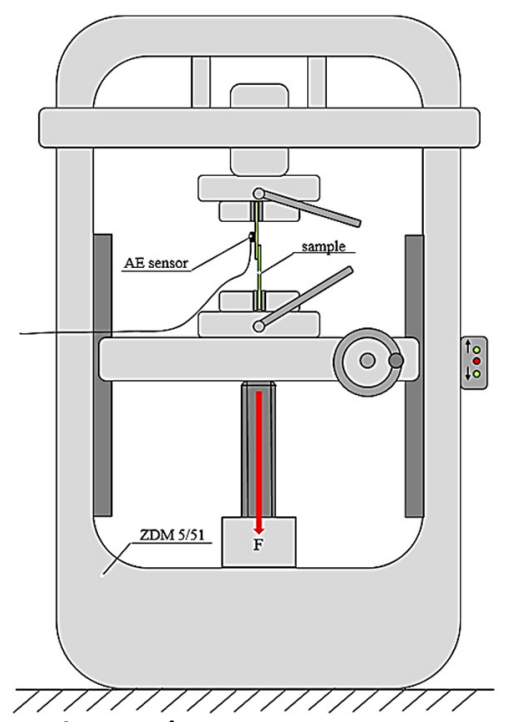

Fig. 4 Scheme of ZDM 5/51
The measured samples were clamped in the jaws and stretched at a speed of $10 \mathrm{~mm} \cdot \mathrm{min}^{-1}$. Every measurement was controlled by acoustic emission using the piezoelectric sensor IDK-09. Signals of acoustic emission were scanned during the tension test and also analysed by means of the measuring system Dakel XEDO for detection the micro cracks in the weld area during loading. The sensor was attached to the specimen by the clamp with the splint fixed in the upper part of sample. The preamplifier of $35 \mathrm{~dB}$ was used. The contact surface of the sensor was covered by the ultrasonic gel.

The RMS (Root Mean Square) of the acoustic emission signal and the number of oversight of Counts 1 and Counts 2 was observed during the measuring. RMS means so-called the effective value of signal indicated in $\mathrm{mV}$. This value come up to quantitative characteristic of measured facts of acoustic emission. The numbers of overshoots of the signal levels $\mathrm{C} 1$ and $\mathrm{C} 2$ characterizing the signal manifestation with a view to time flow and intensity.

\section{RESULTS AND DISCUSSION}

Table 2 below shows the measured values during the experiment. The highest value of maximum signal energy (RMS) was observed, which was correlated with the maximum force that the sample could withstand until rupture.

Table 2

Measured values

\begin{tabular}{ccc}
\hline 0 hour & 100 & 200 \\
& hours & hours
\end{tabular}

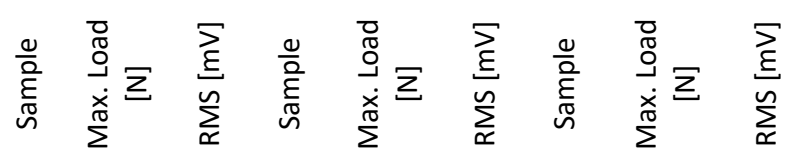

\begin{tabular}{ccccccccc}
\hline 1 & 13496 & 250 & 11 & 11263 & 530 & 21 & 11503 & 620 \\
2 & 13207 & 210 & 12 & 11333 & 520 & 22 & 11968 & 650 \\
3 & 12965 & 210 & 13 & 12113 & 560 & 23 & 11648 & 620 \\
4 & 13320 & 260 & 14 & 11975 & 520 & 24 & 11230 & 600 \\
5 & 13427 & 200 & 15 & 12196 & 580 & 25 & 11981 & 640 \\
6 & 13468 & 210 & 16 & 11063 & 510 & 26 & 12030 & 680 \\
7 & 13056 & 250 & 17 & 12265 & 530 & 27 & 11365 & 620 \\
8 & 12796 & 200 & 18 & 11889 & 530 & 28 & 11360 & 650 \\
9 & 13087 & 220 & 19 & 11356 & 500 & 29 & 12117 & 620 \\
10 & 13069 & 230 & 20 & 12137 & 560 & 30 & 11899 & 630 \\
\hline
\end{tabular}

Figure 5 shows the fracture area of the welded sample after the experiment, i.e., after rupture. 


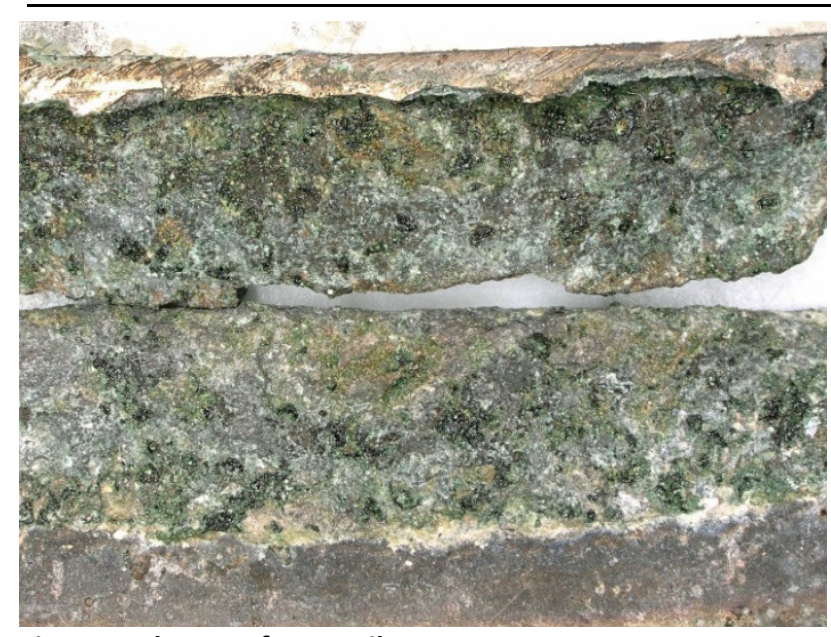

Fig. 5 Crack area after tensile test

Figure 6 shows boxplot based on maximum loading force before rupture. It can be seen that the samples without corrosion exhibited a significantly higher maximum breaking force. Obviously, the samples show lower strength after corrosion degradation.

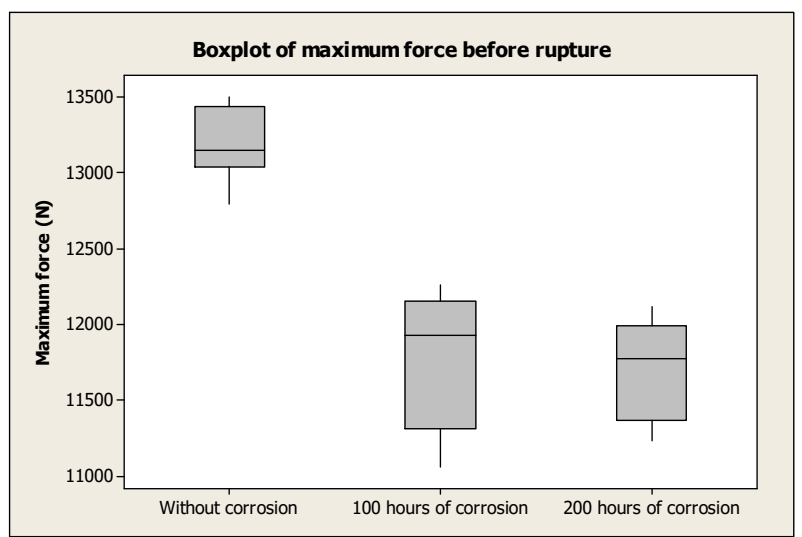

Fig. 6 Boxplot of maximum force before rupture

The maximum force boxplot can be correlated with the maximum RMS boxplot shown in Figure 7 below. There is a direct relationship between the decrease of maximum force (see Fig. 6) and the increase in maximum RMS (see Fig. 7) with exposure time under corrosive conditions.

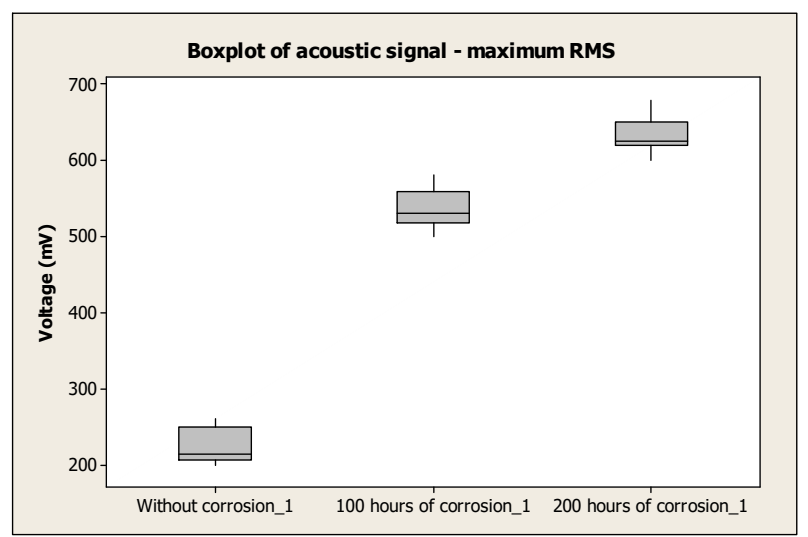

Fig. 7 Boxplot of acoustic signal - maximum RMS
The complete acoustic emission signal that has been recorded is shown in the following figures below (Figures 8 , $9,10)$. The blue curve shows the RMS value, the red and green curves show the counts over the set treshold. One representative figure from each group of specimens was chosen. The Figure 8 shows extremely poor RMS intensity - the tested sample 4 were not corroded. The maximal RMS of the sample 4 is $260 \mathrm{mV}$. The time period 7-45 sec. shows raising activity of acoustic emission signals. The maximal loading of the sample 4 is $13320 \mathrm{~N}$.

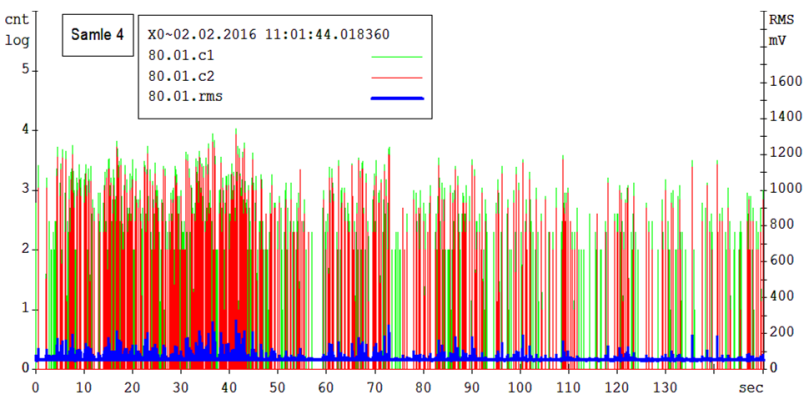

Fig. 8 Record of AE, sample 4-not corroded

From second group the acoustic signal of test sample 17 is shown in Figure 9 below. This sample was exposed to corrosion for 100 hours. There was a decrease in the maximum load to $12265 \mathrm{~N}$. The increased activity of the $A E$ signals is shown, which is caused by rising of the microcracks passing through the magistrate crack through the ruptured surface of the material by the corrosion pits.

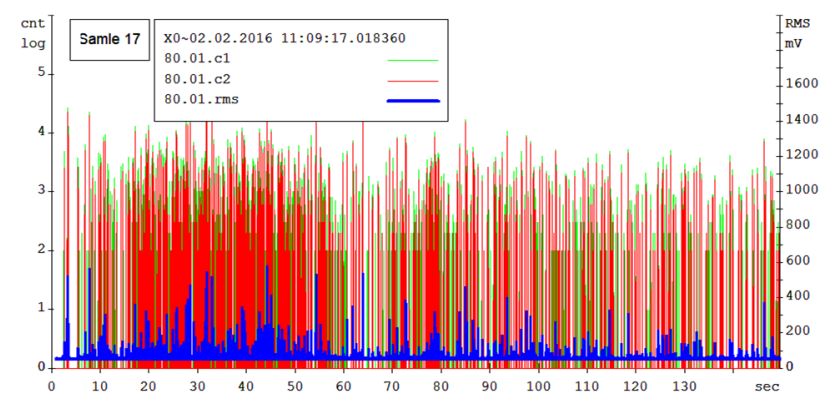

Fig. 9 Record of AE, sample 17-100 hours corroded

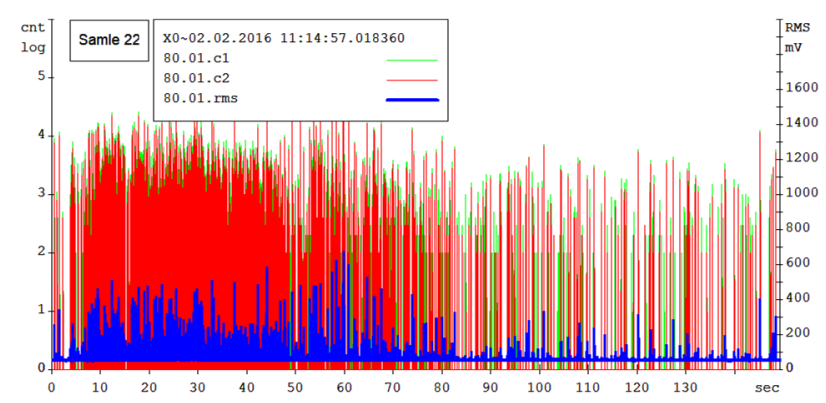

Fig. 10 Record of $A E$, sample $22-200$ hours corroded

Figure 10 shows the acoustic signal of a sample that has been selected from the third group. This is a sample 22 that has been corrosively degraded for 200 hours. 
As reported in the literature [1] and [2] acoustic emission records are directly correlated with the formation of micro-cracks in the internal structure of the material. High voltage of RMS means creation of microcracks before the final break.

\section{CONCLUSION}

It was found, that before the final crack there is a lot of small cracks which are not visible, but it is possible to detect them by acoustic emission system. High voltage of RMS means creation of microcracks before the final break. The sample fracture always occurred in the weld area. Material coherence is risky in this area. Acoustic emission can identify the degree of risk of final crack under load. The values measured indicated that $A E$ detects the occurrence of cracks in the material before the final deformation.

In this experiment, results from the $A E$ measurement of samples during tensile test were presented, whereas the tensile test was supplemented by image of its fracture. From the comparison of tensile load and acoustic values is possible to see the dependency between the course of the decrease of maximum force and an increase of RMS acoustic signal.

The main benefit of the use of acoustic emission in the load of weldments is the possibility of predicting the risk state. Counts and RMS identify microcrack formation much before the final fracture occurs. By using acoustic emission for welded work under load, large losses can be avoided.

\section{ACKNOWLEGEMENT}

This paper was created with financial support of the grant project KEGA no. 039SPU-4/2017 "Innovative teaching subjects, focusing on quality management, metal machining and metrology interact on practical requirements". The research has been supported by the project TP 6/2017: Defectoscopic quality assessment of technical and organic materials; financed by IGA $A F$ MENDELU.

\section{REFERENCES}

[1] P. Dostal, and P. Communeau, "Visualisation of Corrosion Acoustic Signals Using Quality Tools" Acta Universitatis Agriculturae et Silviculturae Mendelianae Brunensis vol. 62, pp. 65-69, No. 3, 2014.

[2] P. Dostal, M. Cerny, J. Lev, and D. Varner, "Proportional Monitoring of the Acoustic Emission in Crypto-conditions" Acta Universitatis Agriculturae et Silviculturae Mendelianae Brunensis, vol. 66, pp. 31-38, No. 5, 2011.

[3] J. Cerny, and P. Dostal, "Adhesion of Zinc Hot-dip Coatings" Acta Universitatis Agriculturae et Silviculturae Mendelianae Brunensis, vol. 62, pp. 53-64, No. 1, 2014.

[4] J. Votava, V. Kumbar, and P. Dostal, "Degradation Processes of Al-Zn Welded Joints" Acta Universitatis Agriculturae et Silviculturae Mendelianae Brunensis, vol. 62, pp. 571-578, No. 3, 2014.
[5] S. Wang, D. Wang, J. Wang, H. Wang, G. Xu and J. Hong, "Research on Acoustic Emission Source Location Imaging in Aluminum Alloy Plate-type Structure" Journal of Testing and Evaluation, vol. 48, No. 4, 2020.

[6] A. Mostafapour, S. Davooodi, and M. Ghareaghaji, "Acoustic Emission Source Location in Plates using Wavelet Analysis and Cross Time Frequency Spectrum" Ultrasonic, vol. 54, pp. 2055-2062, No. 8, 2014.

[7] Y. Liu, B. J. Pang, R. Q. Chi and W. X. Cao, "Characteristic Analysis of the Hypervelocity impact Acoustic Emission S2 mode in Aluminum Plate" Journal of Astronautic, vol. 37, pp. 1482-1490 No. 12, 2016.

[8] E. Tsangouri, G. Karaiskos, A. Deraemaeker, D. Van Hemelrijck, and D., Aggelis, "Assessment of Acoustic Emission Localization accuracy on Damaged and Healed Concrete" Construction and Building Materials, vol. 129, pp. 163-171, No. December, 2016.

[9] M. Kacalova, J. Majernik, M. Kundratova, and T. Coranic, "Frekvenčná analýza vibrodiagnostického signálu prevodového mechanizmu" Management of Manufacturing Systems, pp. 66-72, 2017.

[10] M. Kacalova, J. Majernik, M. Kundratova, and T. Coranic, "Dynamická analýza ozubenia" Management of Manufacturing Systems, pp. 62-65, 2017.

[11] M. Kacalova, M. Kundratova, T. Coranic, and J. Majernik "Využitie CAE technológií pri pevnostnej kontrole výstupného hriadel'a kužel'ového prevodu" Management of Manufacturing Systems, pp. 73-78, 2017

[12] N. Godin, P. Reynaud, and G. Fantozzi, "Acoustic Emission and Durability of Composite Materials", pp. 181, 2018.

[13] G.S. Wuriti, T. Thomas, and S. Chattopadhyaya, "Prediction of Tensile Failure load for Maraging Steel Weldment by Acoustic Emission Technique" Lecture Notes in Mechanical Engineering, pp. 431-442, 2019.

[14] E.G Na, "Evaluation of Sensitization and Corrosive Damages of the Weldment for SUS 316 Stainless Steel" Journal of Mechanical Science and Technology, vol. 27, pp. 2715-2719, No. September, 2013.

[15] J. Yu, P. Ziehl, J. Caicedo, and F. Matta, "Acoustic Emission Monitoring and Fatigue Prediction of Steel Bridge Components" Proceedings of SPIE - The International Society for Optical Engineering, vol. 8694, 2013.

[16] H. Roy, H.N. Bar, S. Sivaprasad, S. Tarafder, and K.K Ray," Acoustic Emission during Monotonic and Cyclic Fracture Toughness Tests of 304LN Weldments" International Journal of Pressure Vessels and Piping, vol. 87, pp. 543-549, No. 10, 2010.

[17] E.G. Na, S.G Koch, and D.W Lee "AE Evaluation of Relationship between AE Signals and Fracture Mechanisms for the Weldment of Pressure Vessel Steel" Advanced Materials Research, vol. 24-25, pp. 1181-1186, 2007.

[18] K. He, S. Bar, S. Xiao, and X.Li, "Time-Frequency Characteristics of Acoustic Emission Signal for Monitoring of Welding Structural State using Stockwell Transform" Journal of the Acoustical Society of America, vol. 145, pp. 469-479, No. 1, 2019.

[19] J. Mascenik, and S. Pavlenko, "Innovative broad - Spectrum Testing and Monitoring of Belt Transmissions" MM Science Journal, vol. 2018, pp. 2706-2709, No. December, 2018. 
[20] J. Mascenik, "Monitoring of parameters directly influencing performance transfer by belt gear" MM Science Journal, vol. 2017, pp. 1959-1962, No. December, 2017.

[21] S. Olejarova, J. Ruzbarsky, and T. Krenicky, "Vibrodiagnostic analysis" Springer Briefs in Applied Sciences and Technology, pp. 29-37, 2019.
[22] S. Olejarova, J. Ruzbarsky, and T. Krenicky, "Assessment of measurement of vibration sizes" Springer Briefs in Applied Sciences and Technology, pp. 55-74, 2019.

\section{Michal Sustr}

ORCID ID: 0000-0002-3410-6888

Mendel University in Brno

Faculty of Agronomy, Department of Technology and Automobile Transport

Zemedelska 1, 61300 Brno, Czech Republic

\section{Jaroslav Zacal}

ORCID ID: 0000-0003-2780-1476

Mendel University in Brno

Faculty of Agronomy, Department of Technology and Automobile Transport

Zemedelska 1, 61300 Brno, Czech Republic

\section{Peter Dostal}

Mendel University in Brno

Faculty of Agronomy, Department of Technology and Automobile Transport Zemedelska 1, 61300 Brno, Czech Republic

\section{Oldrich Cerny}

ORCID ID: 0000-0001-8666-4219

Mendel University in Brno

Faculty of Agronomy, Department of Technology and Automobile Transport Zemedelska 1, 61300 Brno, Czech Republic

\section{Miroslav Pristavka}

ORCID ID: 0000-0002-7957-4765

Slovak University of Agriculture in Nitra

Faculty of Engineering, Department of Quality and Engineering Technologies

Tr. A. Hlinku 2, 94976 Nitra, Slovak Republic

\section{David Dobrocky}

ORCID ID: 0000-0003-1400-3993

University of Defence

Faculty of Military Technology, Department of Engineer Technologies

Kounicova 156/65, 66210 Brno, Czech Republic

\section{Stefan Gaspar}

ORCID ID: 0000-0002-5314-2120

Technical University of Kosice

Faculty of Manufacturing Technologies with a seat in Presov

Sturova 31, 08001 Presov, Slovak Republic

\section{Jan Pasko}

ORCID ID: 0000-0002-8577-6945

Technical University of Kosice

Faculty of Manufacturing Technologies with a seat in Presov

Sturova 31, 08001 Presov, Slovak Republic 